\title{
What is the association between sedentary behaviour and cognitive function? A systematic review
}

\author{
Ryan S Falck, ${ }^{1}$ Jennifer C Davis, ${ }^{1}$ Teresa Liu-Ambrose ${ }^{1,2}$
}

\begin{abstract}
${ }^{1}$ Faculty of Medicine, Aging, Mobility and Cognitive Neuroscience Laboratory, University of British Columbia, Djavad Mowafaghian Centre for Brain Health, Vancouver, British Columbia, Canada

${ }^{2}$ Department of Physical Therapy, University of British Columbia, Vancouver, British Columbia, Canada
\end{abstract}

\section{Correspondence to}

Teresa Liu-Ambrose, Faculty of Medicine, Aging, Mobility and Cognitive Neuroscience Laboratory, Department of Physical Therapy, Djavad Mowafaghian Centre for Brain Health, University of British Columbia, Vancouver, BC, CA, 212-2177 Wesbrook Mall, Vancouver, British Columbia, Canada V6T 1Z3; teresa. ambrose@ubc.ca

Accepted 7 April 2016 Published Online First 6 May 2016

\begin{abstract}
Aim The increasing rate of all-cause dementia worldwide and the lack of effective pharmaceutical treatments emphasise the value of lifestyle approaches as prevention strategies. Emerging evidence suggests sedentary behaviour is associated with impaired cognitive function. A better understanding of this association would significantly add to our knowledge of how to best promote healthy cognitive ageing. Thus, we conducted a systematic review ascertaining the contribution of sedentary behaviour towards associated changes in cognitive function over the adult lifespan.

Study design Systematic review of peer-reviewed literature examining the association of sedentary behaviour with cognition.

Data sources We searched PubMed, PsycINFO, EBSCO and Web of Science, and reference lists of relevant reviews on sedentary behaviour. Two independent reviewers extracted (1) study characteristics and (2) information regarding measurement of sedentary behaviour and cognitive function. We also assessed study quality using the Strengthening the Reporting of Observational Studies in Epidemiology (STROBE) checklist.
\end{abstract}

Eligibility criteria We limited search results to adults $\geq 40$ years, observational studies published in English since 1990 and studies investigating associations between sedentary behaviour and cognitive function.

Results 8 studies examined the association of sedentary behaviour with cognitive function. 6 studies reported significant negative associations between sedentary behaviour and cognitive function. 8 different measures of sedentary behaviour and 13 different measures of cognitive function were used across all eight studies.

Summary Sedentary behaviour is associated with lower cognitive performance, although the attributable risk of sedentary time to all-cause dementia incidence is unclear. Our systematic review provides evidence that limiting sedentary time and concomitantly engaging in regular moderate-to-vigorous physical activity may best promote healthy cognitive ageing.

\section{INTRODUCTION}

Currently, one new case of all-cause dementia is detected every 4 seconds around the world. ${ }^{1}$ All-cause dementia prevalence is also expected to rise since the number one risk factor is age ${ }^{2}$ and the number of older adults worldwide is increasing. ${ }^{3}$ Thus, the current lack of effective pharmaceutical treatments for all-cause dementia is creating an urgency to develop non- pharmacological strategies to prevent, or at least delay, the onset and progression of the disease. ${ }^{4}$ As a result, lifestyle approaches have become an important line of scientific inquiry and public interest.

Increasing physical activity is one promising strategy to promote or maintain cognitive health in later life. ${ }^{5}$ Strong and accumulating empirical evidence suggests regular physical activity of an intensity $\geq 3.0$ metabolic equivalents (METs) reduces the risk of all-cause dementia by $28 \%{ }^{6}$ Thus, meeting current physical activity guidelines for older adults of $150 \mathrm{~min} /$ week of moderate-to-vigorous physical activity (ie, activity of $\geq 3.0 \mathrm{METs}$ ) may help reduce all-cause dementia risk, prevent other comorbidities including type 2 diabetes and cardiovascular disease, and reduce all-cause mortality. ${ }^{7-9}$ Since most older adults are physically inactive (ie, do not engage in $\geq 150 \mathrm{~min} /$ week of moderate-to-vigorous physical activity) and fall short of these recommendations, ${ }^{10}$ increasing moderate-to-vigorous physical activity among older adults has become a public health priority. As such, it is estimated $17.7 \%$ of Alzheimer's disease cases could be prevented by recommended amounts of moderate-to-vigorous physical activity. ${ }^{11}$

Accumulating evidence also suggests high amounts of sedentary behaviour can increase morbidity and mortality risk. ${ }^{12}$ Sedentary behaviour is defined as any behaviour that incurs $\leq 1.5$ METs and includes behaviours such as sitting, television watching and lying down. ${ }^{13}$ Sedentary behaviour is associated with numerous health risks including type 2 diabetes, ${ }^{14}$ cardiovascular disease ${ }^{15}$ and allcause mortality. ${ }^{16}$ Given the risks of sedentary behaviour to health, recommendations for sedentary time suggest limiting discretionary sedentary time to $<2 \mathrm{~h} /$ day and accumulating $>2 \mathrm{~h}$ /day of light-intensity activity (ie, standing and light walking). ${ }^{17} 18$ Emerging evidence also suggests sedentary behaviour is associated with cognitive function; however, sedentary behaviour is a distinct behaviour from physical activity and thus a systematic review of the current epidemiological evidence is needed. ${ }^{19} 20$

While preliminary evidence suggests sedentary behaviour is associated with cognitive function, it is still unclear what the magnitude of this association is. For example, it is unclear if reducing sedentary behaviour is more important for long-term cognitive health than increasing physical activity. Such empirical evidence is crucial to increasing our understanding of how we can best promote healthy cognitive ageing through lifestyle approaches and 
determining whether public health should focus on reducing sedentary behaviour, increasing moderate-to-vigorous physical activity or both to reduce all-cause dementia prevalence. Thus, our objective was to systematically review the epidemiological evidence regarding how sedentary behaviour is associated with cognitive function throughout the adult lifespan.

\section{METHODS}

\section{Summary of search strategy}

We conducted a systematic review regarding the association between sedentary behaviour and cognitive function. In accordance with the Preferred Reporting Items for Systematic Reviews and Meta-Analyses (PRISMA) statement, ${ }^{21}$ we searched PubMed, PsycINFO, EBSCO and Web of Science between 1 January 1990 and 6 February 2016. Included in our search terms were the following keywords: sedentary behaviour terms (sedentary behaviour, physical inactivity, television time, TV time, screen time); cognition terms (cognition, cognitive function, brain function, executive function, memory, dementia, Alzheimer's disease) and age terms (older adults, elders, elderly, ageing, aged, 40+ years). This process was repeated until all search term combinations were performed. A sample of the search strategy used for studies investigating the association between sedentary behaviour and cognitive function is provided in figure $1 \mathrm{~A}$.

\section{Study selection}

We selected peer-reviewed, published and observational studies that included adults aged 40 years and older that measured sedentary behaviour as an exposure and cognitive function as an outcome. Articles mentioning sedentary behaviour and cognition in either the title or abstract were initially included for fulltext review.

\section{Inclusion and exclusion criteria}

We included studies if they were (1) observational studies (ie, cohort, case-control or cross-sectional); (2) peer reviewed and (3) published in the English language between 1 January 1990 and 6 February 2016. All studies included clearly described participants as adults aged 40 years and older at baseline assessment and measured sedentary behaviour at baseline assessment or over time with the purpose of assessing risk (ie, exposure). Additionally, the studies included measured cognitive function at baseline assessment or over time with the purpose of determining change associated with increased sedentary behaviour (ie, outcome).

We excluded articles if they were (1) not peer reviewed and (2) not published in the English language. Since we were only interested in observational studies, interventions designed to reduce sedentary behaviour were not included.

\section{Data extraction}

Two authors (RSF and JCD) initially screened and identified studies based on the study title and abstract. Duplicates and articles failing to meet inclusion criteria were removed. The remaining full-text articles were reviewed by RSF and JCD to determine eligibility. Any disagreements were resolved by a third reviewer (TL-A).

Two raters (RSF and JCD) independently extracted data from all articles included; discrepancies were discussed and reviewed by a third party (TL-A). Data were extracted from the included articles using a custom data extraction form developed by RSF and JCD. We extracted the following categories: (1) study design; (2) participant characteristics, setting and length of follow-up; (3) measure of exposure (ie, sedentary behaviour); (4) measure of outcome (ie, cognitive function) and (5) main findings.

For exposure measures (ie, sedentary behaviour), we extracted the (1) instrument name; (2) exposure definition (eg, sedentary
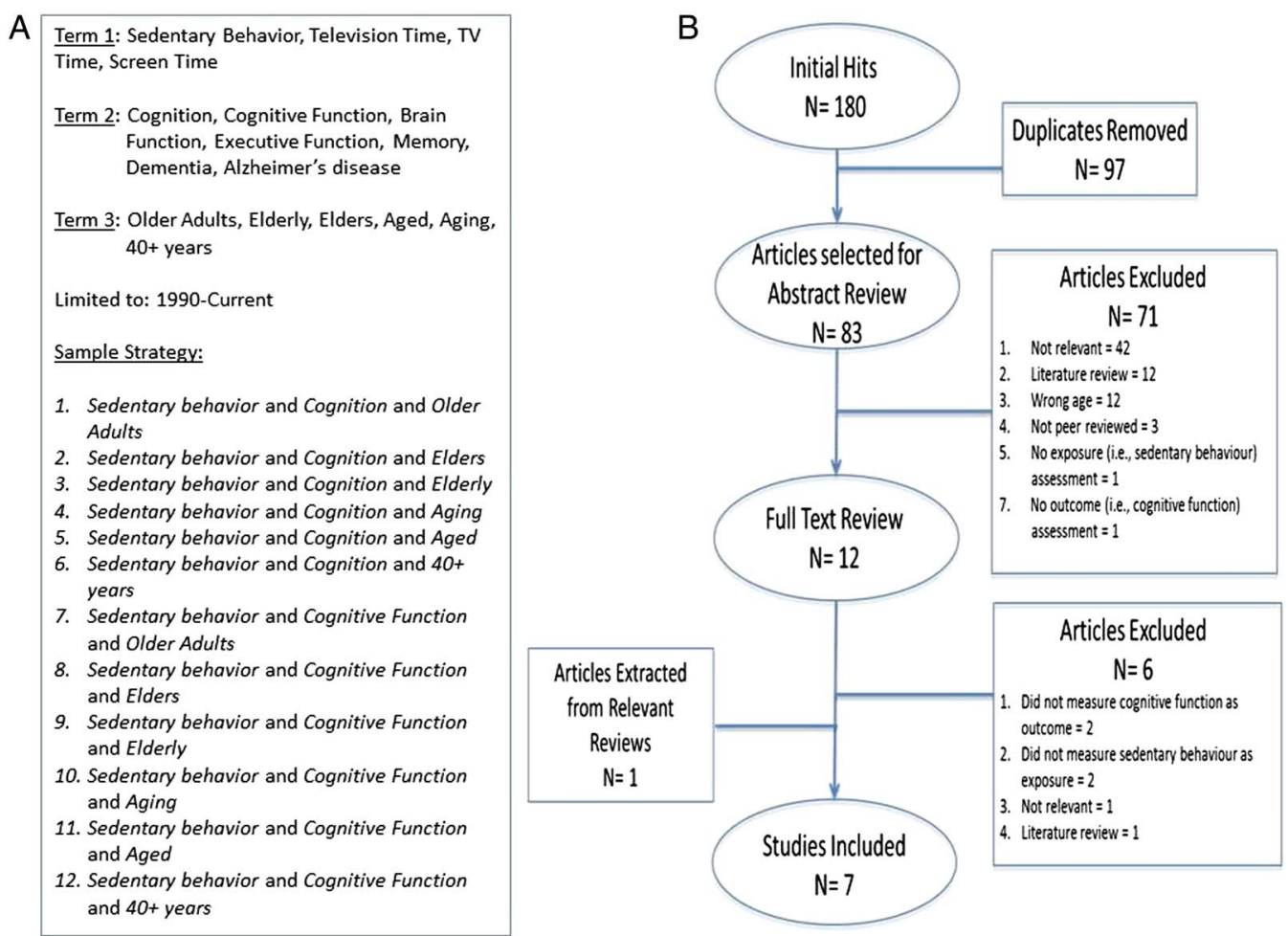

Figure 1 (A) Simplified search strategy. (B) Flow chart of study selection. 
Table 1 Study characteristics

\begin{tabular}{|c|c|c|c|}
\hline $\begin{array}{l}\text { Publication and } \\
\text { study design }\end{array}$ & $\begin{array}{l}\text { Participants, country, setting } \\
\text { and length of follow-up }\end{array}$ & $\begin{array}{l}\text { Sedentary behaviour (exposure } \\
\text { assessment) }\end{array}$ & $\begin{array}{l}\text { Cognitive function (outcome } \\
\text { assessment) }\end{array}$ \\
\hline \multicolumn{4}{|l|}{ Cohort designs } \\
\hline $\begin{array}{l}\text { Hamer and } \\
\text { Stamatakis }^{23} \\
\text { Cohort design }\end{array}$ & $\begin{array}{l}6359 \text { men and women from the } \\
\text { English Longitudinal Study of } \\
\text { Ageing } \\
\text { England } \\
\text { 2-year follow-up }\end{array}$ & $\begin{array}{l}\text { Self-reported TV viewing considered } \\
\text { sedentary behaviour (SB) }\end{array}$ & $\begin{array}{l}\text { Immediate word recall, delayed } \\
\text { word recall and verbal fluency. } \\
\text { All three used to create a global } \\
\text { cognitive function score (primary } \\
\text { outcome) }\end{array}$ \\
\hline
\end{tabular}

$\begin{array}{ll}\text { Kesse-Guyot } & 2430 \text { participants from the } \\ \text { et }\left.a\right|^{24} & \text { Supplémentation en Vitamines et } \\ \text { Cohort design } & \text { Minéraux Antioxydants Study } \\ & \begin{array}{l}\text { France } \\ \text { 13-year follow-up }\end{array} \\ \text { Kesse-Guyot } & 2579 \text { participants who agreed to } \\ \text { et al } & \text { participate in the follow-up } \\ \text { Cohort design } & \begin{array}{l}\text { period of the Supplémentation } \\ \text { en Vitamines et Minéraux }\end{array} \\ & \begin{array}{l}\text { Antioxydants Study } \\ \text { France } \\ \text { 8-year follow-up }\end{array}\end{array}$

Self-administered French version of the Modifiable Activity Questionnaire (MAQ). ${ }^{32}$ Participants reported average time spent at home watching TV (min/day)

Self-administered French Modifiable Activity Questionnaire (MAQ). ${ }^{32}$ Participants asked about average daily time spent with SB (min/day)

8-year follow-up

Case-control designs

Kivipelto et $a l^{26} \quad 1449$ participants from the

Nested Cardiovascular Risk Factors,

case-control Aging and Dementia Study

design (65-79 years)

Finland

Mean follow-up time of 21 years

Lindstrom et $a l^{27}$

Case-control

design

Participants born between 1915 and 1944. 135 cases of

Alzheimer's disease

331 controls recruited from

clinical settings and from the

community.

USA

Cross-sectional designs

Rosenberg et al 307 older adults (67-100 years) Cross-sectional from 11 retirement communities design USA

Self-reported SB assessed using a modified version of the Sedentary Behaviour Questionnaire. ${ }^{39}$ Objective sedentary time measured using ActiGraph GT3X+ accelerometer ${ }^{40}$

Self-reported leisure-time physical activity (PA) dichotomised into categories: active and sedentary (persons who participated in leisure-time PA less than two times per week)

Participants self-reported daily hours of television viewing

Digit span forward and backward (primary outcome), ${ }^{33}$ Delis-Kaplan Trail Making Test, ${ }^{34}$ RI-48 cued recall test, ${ }^{35}$ semantic fluency and phonemic fluency ${ }^{36}$

Phonemic and semantic fluency (primary outcome), ${ }^{36}$ Rl-48 test, ${ }^{35}$ digit span forward and backward, ${ }^{33}$ Delis-Kaplan Trail Making Test $^{34}$

Cognitive status determined via scores on the Mini-Mental State Examination (MMSE), ${ }^{37}$ and all-cause dementia diagnosis (primary outcome) confirmed according to the Diagnostic and Statistical Manual of Mental Disorders $^{38}$

Diagnosed case of Alzheimer's disease (primary outcome)

\section{Trail Making Test ${ }^{41}$}

Hours spent in SB according to the Community Health Activities Model Program for Seniors (CHAMPS) questionnaire $^{42}$

The total amount of time spent sitting, sleeping or lying down was used as an indicator of $\mathrm{SB}^{44}$

Benton Visual Retention Test, ${ }^{45}$ recruited from the Accelerate
CogState computerised battery measured multiple domains of cognition including: psychomotor speed, visual attention, visual recognition and memory (primary outcome $)^{43}$ Trail Making Test ${ }^{41}$ and the Rey-Osterrieth Complex Figure Copy and Recall Tests. ${ }^{46}$ A composite score for cognitive function was then created (primary outcome)
Results

Linear inverse relationship between TV time and cognitive function. Decreased cognition from baseline (EMM $=0.39,95 \% \mathrm{Cl}[0.33$ to 0.45$)$ ) to follow-up (EMM=0.25, $95 \% \mathrm{Cl}$ (0.19 to 0.31$)$ ), but no association between baseline SB and changes in cognitive function

SB associated with decreased global cognitive function $(\beta=-1.28 ; 95 \%$ $\mathrm{Cl}(-2.46$ to -0.11$))$ and decreased verbal memory $(\beta=-1.38 ; 95 \% \mathrm{Cl}$ $(-2.58$ to -0.18$))$ over time

Negative association observed between TV viewing and executive function cross-sectionally $(\beta=-0.98$; $95 \% \mathrm{Cl}(-1.93$ to -0.04$))$, no association between executive function and SB over time

The odds of developing all-cause dementia were 2.07 times greater for participants who were sedentary (95\% Cl 1.12 to 3.86 ) as compared to physically active when controlling for age, sex, follow-up time, education, body mass index (BMI) cholesterol, blood pressure, heart attack, stroke and diabetes

Cases watched significantly more television than controls $(F(1,464)$ $=35.37$ ). The odds of developing Alzheimer's disease increased 1.32 times for every hour of daily television viewing $(95 \% \mathrm{Cl} 1.08$ to 1.62)

Self-reported sedentary time was associated with improved performance on Trails $A$ ( $\beta=-0.01$ \pm 0.01 ) but was not associated with improved executive performance. Objectively measured sedentary time was not associated with Trail Making Test performance

Lower scores on executive function measures associated with increased SB $\left(\beta=0.006 \pm 0.003 ; R^{2}=0.2323\right)$.

Memory scores and processing speed were not associated with increased SB.

Structural equation modelling predicted SB was associated with increased cognitive function $(\beta=0.34)$ study USA behaviour or television time); (3) method of exposure assessment (eg, self-report questionnaire, accelerometry, etc); (4) data collection procedure; (5) statistical methodology and (6) previously established validity and reliability of the instrument. For exposure definitions, sedentary behaviour included time spent engaging in activities with an energy cost of $\leq 1.5$ METs and television time referred to sedentary time spent watching television.

For methods of assessment of cognitive function, we extracted the (1) instrument name; (2) domain of cognitive function 
Table 2 Measures and methods to classify sedentary behaviour

\begin{tabular}{|c|c|c|c|c|c|c|}
\hline Publication & $\begin{array}{l}\text { Name of } \\
\text { measure(s) }\end{array}$ & $\begin{array}{l}\text { Definition of } \\
\text { exposure }\end{array}$ & $\begin{array}{l}\text { Type of exposure } \\
\text { assessment }\end{array}$ & $\begin{array}{l}\text { Data collection } \\
\text { procedure }\end{array}$ & $\begin{array}{l}\text { Statistical methods and } \\
\text { confounder adjustment }\end{array}$ & $\begin{array}{l}\text { Validity and } \\
\text { reliability }\end{array}$ \\
\hline \multicolumn{7}{|l|}{ Cohort studies } \\
\hline $\begin{array}{l}\text { Hamer and } \\
\text { Stamatakis }\end{array}$ & Unknown & TV time & $\begin{array}{l}\text { Subjective measure } \\
\text { Questionnaire } \\
\text { developed for } \\
\text { measuring physical } \\
\text { activity (PA) and } \\
\text { television time }\end{array}$ & $\begin{array}{l}\text { Participants self-reported } \\
\text { daily television time and } \\
\text { engagement in vigorous, } \\
\text { moderate and low-intensity } \\
\text { PA }\end{array}$ & $\begin{array}{l}\text { Type of regression: linear } \\
\text { mixed models with random } \\
\text { effect intercept; } \\
\text { Covariates and confounders: } \\
\text { age, sex, smoking, alcohol, } \\
\text { PA, social status, disability, } \\
\text { chronic illness and body } \\
\text { mass index (BMI) }\end{array}$ & Unknown \\
\hline $\begin{array}{l}\text { Kesse-Guyot } \\
\text { et } a l^{24}\end{array}$ & $\begin{array}{l}\text { Modifiable Activity } \\
\text { Questionnaire } \\
\text { (MAQ) }\end{array}$ & TV time & $\begin{array}{l}\text { Subjective measure } \\
\text { Questionnaire } \\
\text { designed to assess } \\
\text { SB and PA during } \\
\text { past } 12 \text { months }\end{array}$ & $\begin{array}{l}\text { Participants self-reported } \\
\text { average daily time spent } \\
\text { watching TV and } \\
\text { leisure-time PA performed at } \\
\text { least } 10 \text { times for at least } \\
10 \text { min per session over the } \\
\text { past year including the } \\
\text { frequency and duration. } \\
\text { After multiplying the } \\
\text { number of h/week of each } \\
\text { activity by the estimated } \\
\text { metabolic equivalent (MET), } \\
\text { a summary score was } \\
\text { obtained }\end{array}$ & $\begin{array}{l}\text { Type of regression: structural } \\
\text { equation modelling; } \\
\text { Covariates and confounders: } \\
\text { age, gender, education, time } \\
\text { lag between baseline and } \\
\text { cognitive evaluation, } \\
\text { occupation, energy intake, } \\
\text { number of 24-hour records, } \\
\text { BMl, depressive symptoms, } \\
\text { memory issues, diabetes, } \\
\text { hypertension and } \\
\text { cardiovascular disease }\end{array}$ & $\begin{array}{l}\text { Validity: } r=0.65 .{ }^{47} \\
\text { Reliability: ICC }=0.77^{47}\end{array}$ \\
\hline $\begin{array}{l}\text { Kesse-Guyot } \\
\text { et } a l^{25}\end{array}$ & $\begin{array}{l}\text { Modifiable Activity } \\
\text { Questionnaire } \\
\text { (MAQ) }\end{array}$ & $\begin{array}{l}\text { Sedentary } \\
\text { behaviour (SB; TV } \\
\text { time, computer } \\
\text { use, reading) }\end{array}$ & $\begin{array}{l}\text { Subjective measure } \\
\text { Questionnaire } \\
\text { designed to assess } \\
\text { SB and PA during } \\
\text { past } 12 \text { months }\end{array}$ & $\begin{array}{l}\text { Participants self-reported } \\
\text { average daily time spent } \\
\text { watching TV, using a } \\
\text { computer or reading (min/ } \\
\text { day) }\end{array}$ & $\begin{array}{l}\text { Type of regression: principal } \\
\text { component analysis; } \\
\text { Covariates and confounders: } \\
\text { interval between SB } \\
\text { assessment and cognitive } \\
\text { evaluation, age, gender, } \\
\text { education, occupation, } \\
\text { retirement status, tobacco } \\
\text { use, BMI, depressive } \\
\text { symptoms, health status, } \\
\text { heart disease, diabetes, } \\
\text { hypertension and PA }\end{array}$ & $\begin{array}{l}\text { Validity: } r=0.65 .{ }^{47} \\
\text { Reliability: ICC }=0.77^{47}\end{array}$ \\
\hline \multicolumn{7}{|c|}{ Case-control studies } \\
\hline $\begin{array}{l}\text { Kivipelto } \\
\text { et } a^{26}\end{array}$ & Unknown & $\begin{array}{l}\text { SB (leisure-time PA } \\
<2 \times / \text { week) }\end{array}$ & $\begin{array}{l}\text { Subjective measure } \\
\text { Questionnaire } \\
\text { developed by } \\
\text { authors }\end{array}$ & $\begin{array}{l}\text { Participants self-reported } \\
\text { leisure-time PA lasting } \\
>30 \text { min and caused } \\
\text { breathlessness and } \\
\text { sweating. Participants } \\
\text { dichotomised into active } \\
\text { (>2×/week) and sedentary } \\
\text { (<2×/week) }\end{array}$ & $\begin{array}{l}\text { Type of regression: Multiple } \\
\text { logistic regressions; } \\
\text { Covariates and confounders: } \\
\text { age, sex, follow-up time, } \\
\text { education, BMI, cholesterol, } \\
\text { blood pressure, heart attack, } \\
\text { stroke and diabetes mellitus }\end{array}$ & Unknown \\
\hline $\begin{array}{l}\text { Lindstrom } \\
\text { et }\left.a\right|^{27}\end{array}$ & Unknown & $\begin{array}{l}\text { Daily hours of } \\
\text { television viewing }\end{array}$ & $\begin{array}{l}\text { Subjective Measure } \\
\text { Questionnaire } \\
\text { developed by } \\
\text { authors }\end{array}$ & $\begin{array}{l}\text { Participants self-reported } \\
\text { hours/month devoted to TV } \\
\text { viewing at age } 20-39 \text { and } \\
\text { at ages of } 40-59 \text {. Daily TV } \\
\text { viewing hours calculated } \\
\text { from total hours/day spent } \\
\text { watching TV }\end{array}$ & $\begin{array}{l}\text { Type of regression: } \\
\text { unconditional logistic } \\
\text { regression model } \\
\text { Covariates and confounders: } \\
\text { age, gender, income and } \\
\text { education }\end{array}$ & Unknown \\
\hline \multicolumn{7}{|c|}{ Cross-sectional designs } \\
\hline $\begin{array}{l}\text { Rosenberg } \\
\text { et } a l^{28}\end{array}$ & $\begin{array}{l}\text { Self-report measure: } \\
\text { Sedentary Behaviour } \\
\text { Questionnaire } \\
(\text { SBQ) } \\
\text { Objective measure: } \\
\text { ActiGraph GT3X+ } \\
\text { accelerometer }^{40}\end{array}$ & $\begin{array}{l}\text { SBQ: hours spent } \\
\text { in SB } \\
\text { ActiGraph GT3X+: } \\
\text { hours spent in SB }\end{array}$ & $\begin{array}{l}\text { SBQ: subjective } \\
\text { measure } \\
\text { Assessed time spent } \\
\text { during typical day SB } \\
\text { ActiGraph GT3X+: } \\
\text { objective measure } \\
\text { Sedentary assessed } \\
\text { using standard } \\
\text { cut-point of }<100 \\
\text { counts per minute }\end{array}$ & $\begin{array}{l}\text { SBQ: participants reported } \\
\text { time/day spent in SB } \\
\text { including sitting, watching } \\
\text { TV, computer use, reading, } \\
\text { commuting, napping and } \\
\text { other activities. } \\
\text { ActiGraph GT3X+: } \\
\text { participants were included } \\
\text { with at least } 1 \text { valid day of } \\
\text { wear time and } 600 \text { min of } \\
\text { accelerometer data. } \\
\text { Sedentary time was } \\
\text { assessed using the standard } \\
\text { cut-point of }<100 \text { counts } \\
\text { per minute }\end{array}$ & $\begin{array}{l}\text { Type of regression: linear } \\
\text { mixed-effects models } \\
\text { Covariates and confounders: } \\
\text { age, gender, marital and } \\
\text { educational status }\end{array}$ & $\begin{array}{l}\text { SBQ: } \\
\text { Validity: no significant } \\
\text { relationship between } \\
\text { accelerometer counts } \\
\text { and SBQ scores; } \\
\text { Reliability: } \\
\text { ICC }=0.85{ }^{39} \\
\text { ActiGraph GT3X+: } \\
\text { Validity: } r=0.59 .{ }^{48} 49 \\
\text { Reliability: unknown }\end{array}$ \\
\hline
\end{tabular}


Table 2 Continued

\begin{tabular}{|c|c|c|c|c|c|c|}
\hline Publication & $\begin{array}{l}\text { Name of } \\
\text { measure(s) }\end{array}$ & $\begin{array}{l}\text { Definition of } \\
\text { exposure }\end{array}$ & $\begin{array}{l}\text { Type of exposure } \\
\text { assessment }\end{array}$ & $\begin{array}{l}\text { Data collection } \\
\text { procedure }\end{array}$ & $\begin{array}{l}\text { Statistical methods and } \\
\text { confounder adjustment }\end{array}$ & $\begin{array}{l}\text { Validity and } \\
\text { reliability }\end{array}$ \\
\hline $\begin{array}{l}\text { Steinberg } \\
\text { et } a l^{29}\end{array}$ & $\begin{array}{l}\text { Community Health } \\
\text { Activities Model } \\
\text { Program for Seniors } \\
\text { (CHAMPS) } \\
\text { questionnaire }^{42}\end{array}$ & Hours spent in SB & $\begin{array}{l}\text { Subjective measure } \\
\text { Assessed frequency } \\
\text { and duration of } 40 \\
\text { different activities } \\
\text { undertaken by older } \\
\text { adults }\end{array}$ & $\begin{array}{l}\text { Participants self-reported } \\
\text { weekly frequency and } \\
\text { duration of } 40 \text { different } \\
\text { activities using the CHAMPS } \\
\text { questionnaire }\end{array}$ & $\begin{array}{l}\text { Type of regression: linear } \\
\text { regression analyses } \\
\text { Covariates and confounders: } \\
\text { age, sex, race, and } \\
\text { education }\end{array}$ & $\begin{array}{l}\text { Validity: } r=0.29 \\
\text { Test-retest reliability: } \\
\mathrm{ICC}=0.76^{50}\end{array}$ \\
\hline Vance et $a l^{30}$ & Unknown & $\begin{array}{l}\text { Total amount of } \\
\text { time spent sitting, } \\
\text { sleeping or lying } \\
\text { down used as an } \\
\text { indicator of SB }\end{array}$ & $\begin{array}{l}\text { Subjective measure } \\
\text { Questionnaire } \\
\text { adapted from } \\
\text { Paffenbarger } \\
\text { questionnaire }^{44}\end{array}$ & $\begin{array}{l}\text { Participants self-reported } \\
\text { how many hours per day } \\
\text { spent seated, lying down } \\
\text { and sleeping }\end{array}$ & $\begin{array}{l}\text { Types of regression: latent } \\
\text { growth model; } \\
\text { Covariates and confounders: } \\
\text { age, depression and PA }\end{array}$ & Unknown \\
\hline
\end{tabular}

assessed; (3) method for assessing cognitive function; (4) statistical methodology and (5) previously established validity and reliability of the instrument. Given the limited number of studies available and the heterogeneity of samples used in these studies, we did not perform a meta-analysis.

\section{Assessment of study quality}

Two authors (RSF and JCD) assessed the quality of the articles via the Strengthening the Reporting of Observational Studies in Epidemiology (STROBE) guidelines. ${ }^{22}$ The STROBE checklist contains 22 separate items to identify the quality of reporting for observational studies. In summary, we assessed study quality based on the following components: (1) an informative and balanced abstract; (2) clear scientific background, rationale, objectives and hypothesis; (3) clear description of study design, methodology, outcomes and exposures, and statistical analyses; (4) clear description of potential biases and how these were limited; (5) clear description of study participants, incidence of loss to follow-up and reporting of outcomes and exposures; (6) clear reporting of all results and analyses; (7) clear summarisation of study findings with reference to study objectives; (8) clear description of the limitations of the study and (9) a cautious overall interpretation of the findings with reference to the generalisability of the findings.

Two raters (RSF and JCD) independently rated the quality of the studies and achieved consensus through discussion $(K=0.90)$. Discrepancies were settled by a third author (TL-A). We used a binary system $(+=$ Yes, $-=$ No) for each item of interest on the STROBE checklist. High-quality studies were defined as studies missing fewer than three criteria of the STROBE checklist, while low-quality studies were defined as studies missing three or more criteria.

\section{RESULTS}

\section{Search results and study characteristics}

Figure 1A, B describes the results of the search strategy for articles examining the association of sedentary behaviour with cognitive function. Of the 485 articles initially identified by title and abstract screening, our final systematic review included 8 articles. $^{23-30}$

Study characteristics are described in table 1 . Three studies used a cohort design, ${ }^{23-25}$ one was a nested case-control design, ${ }^{26}$ one used a case-control design ${ }^{27}$ and three studies used a cross-sectional design. ${ }^{27-29}$ The average follow-up time for the cohort studies was 7.67 years, ${ }^{23-25}$ and the follow-up time for the nested case-control study was 21 years. ${ }^{26}$ Sample sizes ranged from 125 to 6359 participants with samples from England, Finland, France and the USA.

\section{Measurement of sedentary behaviour}

Measurement of sedentary behaviour varied considerably with a total of eight different measures used across the eight studies, as described in table 2. All eight studies measured exposure to sedentary behaviour via subjective methods,,$^{23-30}$ and one study ${ }^{28}$ measured sedentary behaviour via an objective method (accelerometry). Five studies measured exposure as sedentary time (ie, time spent sitting, lying down or sleeping $)^{25-30}$ and four studies measured exposure as TV time..$^{23-25} 27$ One study measured exposure as TV time and sedentary time. ${ }^{25}$

Five studies examined sedentary behaviour using a previously developed questionnaire. ${ }^{24} 25 \quad 28-30$ Two studies ${ }^{24} 25$ used the Modifiable Activity Questionnaire (MAQ) to assess sedentary behaviour, $^{32}$ a single study $^{29}$ used the Community Health Activities Model Program for Seniors (CHAMPS) questionnaire $^{42}$ another study $^{28}$ used the Sedentary Behaviour Questionnaire $(\mathrm{SBQ})^{39}$ and the last study ${ }^{30}$ used an unnamed questionnaire developed from previous investigations to assess sedentary time. ${ }^{44}$ Each of the four questionnaires showed evidence of validity and reliability; however, only the CHAMPS, MAQ and SBQ were previously validated against a criterion measure. 394750

A single study ${ }^{28}$ used an accelerometer, the ActiGraph $\mathrm{GT} 3 \mathrm{X}+{ }^{40}$ to measure sedentary behaviour objectively. Accelerometers show good evidence of validity; ${ }^{48} 49$ however, there is no current minimum wear standard for reliable sedentary behaviour estimates.

\section{Measurement of outcomes from sedentary behaviour}

Table 3 describes the measures of cognitive function used. Thirteen different measures of cognitive function were used across the eight studies. ${ }^{23-30}$ Studies examined the following areas of cognition: (1) five measured memory; ${ }^{23242930}$ (2) five measured executive function; ; $^{2528} 28$ (3) four measured processing speed; ${ }^{23} 28-30$ (4) two measured incidence of cognitive impairment or all-cause dementia ${ }^{26} 27$ and (5) one measured perceptual organisation and planning. ${ }^{30}$ Three studies created scores for global cognitive function. ${ }^{23} 2930$

\section{Assessment of memory}

The constructs of memory measured were non-descriptive memory (ie, unspecified by the authors as to what construct of memory the test measured), lexical-semantic memory, working memory, visual memory and episodic memory. Non-descriptive 
Table 3 Measures and methods for outcome assessment (ie, cognitive function)

\begin{tabular}{|c|c|c|}
\hline Publication & $\begin{array}{l}\text { Domain of cognitive function } \\
\text { assessed (name of measure) }\end{array}$ & Data collection procedure \\
\hline \multicolumn{3}{|c|}{ Cohort designs } \\
\hline $\begin{array}{l}\text { Hamer and } \\
\text { Stamatakis }^{23}\end{array}$ & $\begin{array}{l}\text { Processing speed (immediate word } \\
\text { recall), memory (delayed word recall) } \\
\text { and executive function (verbal } \\
\text { fluency) }\end{array}$ & $\begin{array}{l}\text { Immediate word recall: read } 10 \text { words } \\
\text { and recalled as many words as possible } \\
\text { immediately after. Delayed word recall: } \\
\text { using same list, recalled words after they } \\
\text { completed other cognitive function tests. } \\
\text { Verbal fluency: named as many animals } \\
\text { as possible in } 1 \text { min. A global cognitive } \\
\text { function score calculated from the sum of } \\
\text { standardised scores on each test }\end{array}$ \\
\hline $\begin{array}{l}\text { Kesse-Guyot } \\
\text { et } a l^{24}\end{array}$ & $\begin{array}{l}\text { Lexical-semantic memory (phonemic } \\
\text { fluency and semantic fluency }{ }^{36} \text { ), } \\
\text { episodic memory (RI-48 test }{ }^{35} \text { ), } \\
\text { working memory (Digit span forward } \\
\text { and backward }{ }^{33} \text { ), Executive function } \\
\text { (Delis-Kaplan Trail Making Test }{ }^{34} \text { ) }\end{array}$ & $\begin{array}{l}\text { Phonemic fluency: cited as many words } \\
\text { as possible in } 2 \text { min beginning with the } \\
\text { letter ' } p \text { '. Semantic fluency: named as } \\
\text { many animals as possible in } 2 \text { min. RI- } 48 \\
\text { test: delayed cued recall test. Digit span } \\
\text { forward and backward: repeated } \\
\text { sequence of seven digits, forward and } \\
\text { backward. Trail Making Test: connecting } \\
\text { numbers and letters alternating between } \\
\text { the two series }\end{array}$ \\
\hline
\end{tabular}

Analyses used

Validity and reliability

Type of regression: linear mixed Unknown

models with random effect intercept:

Covariates and confounders: age sex

smoking, alcohol, physical activity,

social status, disability, chronic

illness and body mass index (BMI)

Type of regression: structural

Phonemic fluency: cited as many words as possible in 2 min beginning with ' $p$ '. Semantic fluency: named as many animals as possible in 2 min. RI-48 test: delayed cued recall test. Digit span forward and backward: repeated sequence of 7 digits, forward and backward. Trail Making Test: connecting numbers and letters alternating between the two series

Case-control designs

Kivipelto Screened for cognitive impairment and et $a^{26} \quad$ all-cause dementia

Lindstrom Screened for $A D$

et $a l^{27}$ esigns

Cross-sectional designs

Rosenberg Executive function and processing et $a^{28} \quad$ speed (Trail Making Test ${ }^{41}$ )

Steinberg et $a l^{29}$

CogState computerised battery. ${ }^{43}$ Cognitive tests assessed: (1) processing speed; (2) visual attention, recognition and memory; (3) verbal learning and memory; (4) immediate recall; (5) delayed recall; (6) working memory and (7) problem-solving and reasoning
Mini-Mental State Examination (MMSE) ${ }^{37}$ Type of regression: multiple logistic at screening phase and for those who regressions scored $<24$, neuropsychological examinations conducted to screen for all-cause dementia, according to the Diagnostic and Statistical Manual of Mental Disorders ${ }^{38}$

Cases evaluated by neuropsychological, laboratory and neurological examinations

Trails A was completed first, followed by Trails B. Both items were scored using completion time in seconds, and scores for participants who were unable to complete the examination were set to the maximum value (300 s). Executive function was estimated by subtracting time of Trails A from Trails B Participants administered the CogState tests over a $35 \mathrm{~min}$ period

Type of regression: unconditional logistic regression model

Type of regression: linear mixed-effects models Covariates and confounders: age, gender, marital and educational status.

Type of regression: linear regression analyses equation modelling;

Covariates and confounders: age gender, education, time lag between baseline and cognitive evaluation, occupation, energy intake, number of 24-hour records, BMI, depressive symptoms, memory issues, diabetes, hypertension and cardiovascular disease

Analyses used

Type of regression: principal component analysis

onemic and semantic fluency: test-retest reliability $r=0.82$. $^{51}$

RI-48: classified $88 \%$ of people with mild cognitive impairment $(\mathrm{MCl})$ or Alzheimer's disease (AD) correctly. ${ }^{35}$

Digit span: $B=0.64$ in confirmatory factor analysis. ${ }^{52}$

Trail Making: $r=-0.38$ compared to Stroop Color Word Score ${ }^{53}$

Validity and reliability

Phonemic and semantic fluency: test-retest reliability $\mathrm{r}=0.82$. $^{51}$

RI-48: classified $88 \%$ of people with $\mathrm{MCl}$ or $\mathrm{AD}$ correctly. ${ }^{35}$

Digit span: $B=0.64$ in confirmatory factor analysis. ${ }^{52}$

Trail Making: $r=-0.38$ compared to Stroop Color Word Score ${ }^{53}$

MMSE: test-re-est reliability: $r=0.89$; validity: $r=0.78$ compared to Verbal IQ and $r=0.66$ compared to performance $\mathrm{IQ}^{54}$ Trail Making Test: Reliability
$\mathrm{r}=0.60-0.90 ;{ }^{41}$ discriminant validity: $\mathrm{t}=16.20$ $(p<0.001)^{54}$

Covariates and confounders: age, sex, race and education 
Table 3 Continued

\begin{tabular}{|c|c|c|c|c|}
\hline Publication & $\begin{array}{l}\text { Domain of cognitive function } \\
\text { assessed (name of measure) }\end{array}$ & Data collection procedure & Analyses used & Validity and reliability \\
\hline Vance et $a l^{30}$ & $\begin{array}{l}\text { Memory (Benton Visual Retention } \\
\text { Test }^{45} \text { ); processing speed and } \\
\text { executive function (Trail Making } \\
\text { Test }^{41} \text { ); visual memory, perceptual } \\
\text { organisation and planning } \\
\text { (Rey-Osterrieth Complex Figure Copy } \\
\text { and Recall Tests }{ }^{46} \text { ) }\end{array}$ & $\begin{array}{l}\text { Benton Visual Retention Test: shown a } \\
\text { series of geometric designs and then } \\
\text { draw from memory. Trail Making Test: } \\
\text { connected } 25 \text { alternating number and } \\
\text { letter circles in sequence as quickly as } \\
\text { possible. Rey-Osterrieth Complex } \\
\text { Figure and Recall Tests: reproduced } \\
\text { complex figure while present and then } \\
\text { from memory }\end{array}$ & $\begin{array}{l}\text { Types of regression: latent growth } \\
\text { model; } \\
\text { Covariates and confounders: age, } \\
\text { depression and physical activity (PA) }\end{array}$ & $\begin{array}{l}\text { Benton Visual Retention } \\
\text { Test: inter-rater reliability } \\
r=0.80-0.90 .^{54} \\
\text { Trail Making Test: reliability } \\
r=0.60-0.90{ }^{41} \text { discriminant } \\
\text { validity: } t=16.20 \\
(p<0.001) .^{54} \\
\text { Rey-Osterrieth Complex } \\
\text { Figure Copy and Recall Tests: } \\
\text { reliability } r=0.90^{46}\end{array}$ \\
\hline
\end{tabular}

memory was measured via delayed word recall ${ }^{31}$ in one study ${ }^{23}$ and the Benton Visual Retention Test ${ }^{45}$ in another study. ${ }^{30}$ Lexical-semantic memory was measured via phonemic and semantic fluency ${ }^{36}$ in two studies. ${ }^{24}{ }^{25}$ Working memory was measured by digit span forward and backward ${ }^{33}$ in two studies. ${ }^{24}{ }^{25}$ Visual memory was assessed using the Rey-Osterrieth Complex Figure Copy and Recall Test ${ }^{46}$ in one study. ${ }^{30}$ Episodic memory was measured via the RI-48 test $^{35}$ in two studies. ${ }^{24} 25$ Among the measures used, the Benton Visual Retention Test, phonemic and semantic fluency, digit span forward and backward, Rey-Osterrieth Complex Figure Copy and Recall Test and the RI-48 have evidence of validity and reliability. ${ }^{46355152}$

\section{Assessment of executive function}

Two studies ${ }^{24} 25$ used the Delis-Kaplan Trail Making Test ${ }^{34}$ to assess executive function, one study ${ }^{23}$ used verbal fluency ${ }^{31}$ and two studies ${ }^{28} 30$ used Trail Making Test. ${ }^{41}$ The Delis-Kaplan Trail Making Test and the Trail Making Test have evidence of validity and reliability. ${ }^{415354}$

\section{Assessment of processing speed}

Processing speed was measured via immediate word recall ${ }^{31}$ in one study $^{23}$ and by Trail Making Test ${ }^{41}$ in two studies. ${ }^{28}{ }^{30}$ Only Trail Making Test has evidence of validity and reliability. ${ }^{415354}$

\section{Assessment of cognitive impairment and all-cause dementia} incidence

One study ${ }^{26}$ used the Mini-Mental State Examination ${ }^{37}$ to screen for cognitive impairment and then conducted neuropsychological examinations to screen for all-cause dementia according to the Diagnostic and Statistical Manual of Mental Disorders. ${ }^{38}$ The other case-control study ${ }^{27}$ screened for cases of Alzheimer's disease using unstated neuropsychological, laboratory and neurological examinations. Evidence of validity and reliability exists for the Mini-Mental State Examination. ${ }^{37}$

\section{Assessment of perceptual organisation and planning}

The study ${ }^{30}$ measuring perceptual organisation and planning used the Rey-Osterrieth Complex Figure Copy and Recall Test. ${ }^{46}$ Evidence of validity and reliability exists for the Rey-Osterrieth Complex Figure and Recall Test. ${ }^{46}$

\section{Assessment of global cognitive function}

One study ${ }^{29}$ used the CogState ${ }^{43}$ computerised battery to assess global cognitive function. Another study ${ }^{23}$ created a standardised global cognitive function score from the three cognitive measures used in the study: immediate word recall, delayed word recall and verbal fluency. ${ }^{31}$ The final study ${ }^{30}$ to measure global cognitive function used a standardised score from the Benton Visual Retention Test, ${ }^{45}$ Trail Making Test $^{41}$ and Rey-Osterrieth Complex Figure Copy and Recall Test. ${ }^{46}$ Only the CogState computerised battery has evidence of validity and reliability as a global cognition measure. ${ }^{55}$

\section{Quality assessment}

Studies varied considerably in quality as shown in table 4. On average, studies met 19 of the 22 specific criteria of the STROBE checklist. $^{23-30}$ One article met all guidelines for the reporting of information; ${ }^{24}$ however, three studies failed to address four or more different criteria of the STROBE checklist. ${ }^{27-29}$ All four of the high-quality studies found negative associations between sedentary behaviour and cognitive function. ${ }^{23-26}$

The common issues were failure to report (1) study size $(\mathrm{n}=4) ;^{27-30}(2)$ information about the design in the title and abstract $(n=4) ;^{26} \quad 28-30(3)$ potential biases $(n=4)^{27-30}$ and (4) specific objectives and hypotheses $(n=3) .{ }^{23} 2629$ Other issues in study quality included failure to report (1) eligibility criteria $(\mathrm{n}=1) ;{ }^{27}(2)$ sources of data and method of assessment $(\mathrm{n}=1) ;^{27}$ (3) describing statistical analyses $(n=1) ;^{25}$ (4) providing a cautious overall interpretation of the study $(n=1) ;^{28}(5)$ discussing the generalisability of the findings $(n=1)^{28}$ and (6) outcomes, exposures and potential confounders $(n=1) .^{28}$

\section{Findings from studies on the association of sedentary behaviour with cognitive function}

In total, six studies found associations between increased sedentary behaviour and decreased cognitive function. ${ }^{23-28}$ Two studies found associations between increased sedentary behaviour and improved cognitive function. ${ }^{28} 30$

\section{Cohort designs}

Among the cohort studies, one study found an association between increased sedentary behaviour and decreased cognitive function over time. ${ }^{24}$ The other two studies found associations between increased sedentary behaviour and lower cognitive function at baseline, but no association between sedentary behaviour and cognition over time. ${ }^{2325}$

\section{Case-control designs}

The nested case-control study found the odds of developing allcause dementia were higher for individuals who engaged in more sedentary behaviour. ${ }^{26}$ In addition, the other case-control study found that individuals who watched more hours of television per day had higher odds of developing Alzheimer's disease in later life. ${ }^{27}$ 
Table 4 Quality assessment for studies on the relationship of sedentary behaviour with cognitive function

\begin{tabular}{|c|c|c|c|c|c|c|c|c|}
\hline \multirow[b]{2}{*}{$\begin{array}{l}\text { STROBE } \\
\text { checklist* }\end{array}$} & \multicolumn{3}{|l|}{ Cohort designs } & \multicolumn{2}{|c|}{ Case-control designs } & \multicolumn{3}{|c|}{ Cross-sectional designs } \\
\hline & $\begin{array}{l}\text { Hamer and } \\
\text { Stamatakis }^{23}\end{array}$ & $\begin{array}{l}\text { Kesse-Guyot } \\
\text { et } a l^{24}\end{array}$ & $\begin{array}{l}\text { Kesse-Guyot } \\
\text { et } a l^{25}\end{array}$ & $\begin{array}{l}\text { Kivipelto } \\
\text { et } \mathrm{al}^{26}\end{array}$ & $\begin{array}{l}\text { Lindstrom } \\
\text { et } a l^{27}\end{array}$ & $\begin{array}{l}\text { Rosenberg } \\
\text { et } a l^{28}\end{array}$ & $\begin{array}{l}\text { Steinberg } \\
\text { et } a l^{29}\end{array}$ & $\begin{array}{l}\text { Vance } \\
\text { et }\left.a\right|^{30}\end{array}$ \\
\hline 1 & + & + & + & - & + & - & - & - \\
\hline 2 & + & + & + & + & + & + & + & + \\
\hline 3 & - & + & + & - & + & + & - & + \\
\hline 4 & + & + & + & + & + & + & + & + \\
\hline 5 & + & + & + & + & + & + & + & + \\
\hline 6 & + & + & + & + & - & + & + & + \\
\hline 7 & + & + & + & + & + & - & + & + \\
\hline 8 & + & + & + & + & - & + & + & + \\
\hline 9 & + & + & + & + & - & - & - & - \\
\hline 10 & + & + & + & + & - & 1 & - & - \\
\hline 11 & + & + & + & + & + & + & + & + \\
\hline 12 & + & + & - & + & + & + & + & + \\
\hline 13 & + & + & + & + & + & + & + & + \\
\hline 14 & + & + & + & + & + & + & + & + \\
\hline 15 & + & + & + & + & + & + & + & + \\
\hline 16 & + & + & + & + & + & + & + & + \\
\hline 17 & + & + & + & + & + & + & + & + \\
\hline 18 & + & + & + & + & + & + & + & + \\
\hline 19 & + & + & + & + & + & + & + & + \\
\hline 20 & + & + & + & + & + & - & + & + \\
\hline 21 & + & + & + & + & + & - & + & + \\
\hline 22 & + & + & + & + & + & + & + & + \\
\hline $\begin{array}{l}{ }^{*} \text { The STRO } \\
\text { 1. Indicates } \\
\text { 2. Gives th } \\
\text { 3. States sp } \\
\text { 4. Presents } \\
\text { 5. Describe } \\
\text { 6. Clearly d } \\
\text { 7. Clearly d } \\
\text { 8. Gives so } \\
\text { 9. Describe } \\
\text { 10. Explain } \\
\text { 11. Explain } \\
\text { 12. Describ } \\
\text { 13. Reports } \\
\text { 14. Gives C } \\
\text { 15. Reports } \\
\text { 16. Clearly } \\
\text { 17. Reports } \\
\text { 18. Summa } \\
\text { 19. Discuss } \\
\text { 20. Provide } \\
\text { 21. Discuss } \\
\text { 22. Gives tl }\end{array}$ & $\begin{array}{l}\text { cklist asks the foll } \\
\text { design in title an } \\
\text { tific background a } \\
\text { objectives and hy } \\
\text { ements of study d } \\
\text { g, location, expos } \\
\text { eligibility criteria } \\
\text { outcomes, expost } \\
\text { f data and clearly } \\
\text { tial bias. } \\
\text { study size was arr } \\
\text { quantitative varia } \\
\text { statistical analyses } \\
\text { er of individuals } \\
\text { eristics of study pa } \\
\text { er of events (outc } \\
\text { es the main result } \\
\text { her analyses done } \\
\text { ey findings with r } \\
\text { tations of the stuc } \\
\text { ttious overall inter } \\
\text { generalisability of } \\
\text { rces of funding an }\end{array}$ & $\begin{array}{l}\text { formation (+=Rep } \\
\text { and provides an } \\
\text { le. } \\
\text { ow-up and releva } \\
\text { lods of selecting } \\
\text { ntial confounders } \\
\text { method of assess } \\
\text { handled in analy } \\
\text { age of study and } \\
\text { and indicates nu } \\
\text { /or exposures). } \\
\text { yses. } \\
\text { to study objective } \\
\text { of the study. } \\
\text { ngs. } \\
\text { the funders. }\end{array}$ & $\begin{array}{l}-=\text { Not reported } \\
\text { native and balan } \\
\text { es. } \\
\text { pants. } \\
\text { ictors and effect } \\
\text { reasons for non- } p \\
\text { of missing data. }\end{array}$ & ers. & & & & \\
\hline
\end{tabular}

\section{Cross-sectional designs}

The results of the cross-sectional studies were mixed. One study found associations between increased sedentary behaviour and lower cognitive function. ${ }^{29} \mathrm{~A}$ second study found sedentary behaviour was positively associated with cognitive function. ${ }^{30}$ The final cross-sectional study found subjectively measured sedentary behaviour was positively associated with processing speed; however, there was no association between sedentary behaviour and cognitive function when measured objectively. ${ }^{28}$

\section{DISCUSSION}

\section{Summary of main findings}

Our results indicate sedentary behaviour is associated with reduced cognitive function over the lifespan. Importantly, all four of the high-quality studies found sedentary behaviour is associated with poorer cognitive function. However, the heterogeneity in the current methods used to quantify sedentary behaviour and cognitive function is the major barrier to determining the precise magnitude of this relationship. We also found only one study used an objective measure of sedentary behaviour and a number of exposure measures lacked evidence of validity and reliability.

Furthermore, two of the three longitudinal studies had follow-up periods of $<10$ years, which may account for the significant findings at baseline but not over time. ${ }^{23}{ }^{25}$ Changes in cognition occur gradually over the adult lifespan,${ }^{56}$ often with detectable changes occurring after the age of $60 .{ }^{57}$ As such, studies with short-term follow-ups (ie, $<10$ years) may not detect meaningful associations between changes in cognition and lifestyle behaviours.

\section{Comparison of the findings with the literature}

A large body of work on the association between physical activity and improved cognitive function exists ${ }^{6}$; however, far less is 
known about the association of sedentary behaviour with cognition. Some preliminary findings have suggested that sedentary behaviour is associated with later-life cognitive impairment but have also noted a lack of epidemiological evidence needed to draw strong conclusions. ${ }^{19} 20$

Our review suggests sedentary behaviour is indeed associated with impaired cognitive function and all-cause dementia risk. Specifically, higher quality studies ${ }^{23-26}$ and those of stronger epidemiological evidence (ie, cohort or case-control design) ${ }^{23-27}$ all found associations between increased sedentary behaviour and poorer cognition. Moreover, the current evidence suggests an association by meeting five of the nine epidemiological criteria for causation. ${ }^{58}$ Specifically, the criteria met include: (1) consistent findings across persons, places and circumstances; (2) evidence of temporality; (3) evidence of a dose-response relationship; (4) a plausible mechanism by which exposure leads to outcome and (5) by analogy, the exposure is associated with outcome. Importantly, our systematic review found consistency in the findings, ${ }^{23-29}$ evidence of temporality 2427 and evidence of a dose-response relationship. ${ }^{23-25} 29$

In addition to our findings, a plausible mechanism by which sedentary behaviour is associated with cognitive decline is emerging. Recent data suggest prolonged sedentary time impairs glucose and lipid metabolism, ${ }^{59}$ which are both recognised as risk factors for cognitive decline and all-cause dementia. ${ }^{60} \quad 61$ There is also evidence that sedentary behaviour is related to cognitive decline by analogy. Briefly, sedentary behaviour is associated with many chronic diseases ${ }^{14} \quad 15 \quad 16 \quad 62$ which are also associated with cognitive impairment and dementia risk. ${ }^{63-65}$ Thus, the evidence collectively suggests sedentary behaviour is a risk factor for later-life cognitive impairment and all-cause dementia risk.

\section{Assessment of sedentary behaviour}

While our findings suggest there is now enough evidence to consider sedentary behaviour a risk factor for cognitive decline and dementia, the current measurement of sedentary behaviour still has some limitations. First, only one of the studies reviewed measured sedentary behaviour with an objective measure. ${ }^{28}$ While there is no one best measure for assessing sedentary behaviour, $^{66}$ and objective measures and subjective measures have limitations, ${ }^{67}$ objective measures are considered to be more accurate and reliable because they eliminate recall bias. ${ }^{68}$ This is because physical activity participation among older adults is often intermittent, sporadic or unstructured, which makes recall extremely difficult; ${ }^{69}$ thus, older adults may unintentionally over-report their sedentary behaviour. ${ }^{70}$ However, this does not mean subjective methods of assessing sedentary behaviour are useless. Complete data from objective measures have an inherent selection bias which limits the generalisability of the findings, and objective assessment may miss components or dimensions of sedentary behaviour which may be health protective. ${ }^{68}$ Thus, future research examining the association of sedentary behaviour with cognitive function should use both objective and subjective measures whenever possible. ${ }^{71}$

Second, four of the eight studies we reviewed used measures of sedentary behaviour with no previous evidence of validity or reliability. ${ }^{23} 262730$ Validity and reliability are important for making sound interpretations from tests, and thus the lack of evidence of either calls into question the conclusions drawn from these studies. ${ }^{72} 73$ The continued use of measures without evidence of validity and reliability is making the conclusions drawn from these studies questionable at best, and downright wrong at worst. ${ }^{74}$
Finally, the construct of sedentary behaviour was misclassified in several of the studies. For example, Kivipelto et $a l^{26}$ categorised participants as sedentary based on self-reported leisuretime physical activity of less than twice per week. Yet, the absence of physical activity does not define sedentary behaviour, ${ }^{14}$ and thus misclassification in the literature poses challenges to accurately assessing the association between sedentary behaviour and cognitive function.

\section{Assessment of cognitive function}

While the current measurement of cognitive function in the studies reviewed appears to be more rigorous than the methods used to assess sedentary behaviour, there are still concerns. First, the numerous measures of cognitive function currently in use are obfuscating the relationship between sedentary behaviour and cognition. The eight studies we reviewed used a total of 13 measures of cognitive function. Specifically, the studies assessed memory by six different tests, executive function by four tests, processing speed by two methods, cognitive impairment by two methods and global cognitive function by three methods. With such a wide variety of measures used to assess each domain of cognitive function, comparing study results is extremely difficult. On the basis of the heterogeneity of measures, we recommend future studies use the following instruments for each domain of cognition to allow comparisons across studies: (1) RI-48 for memory; (2) Trail Making Task for executive function; (3) immediate word recall for processing speed; (4) the Rey-Osterrieth Complex Figure Copy and Recall Test for perceptual organisation and planning and (5) the Montreal Cognitive Assessment (MoCA ${ }^{75}$ for global cognition.

In addition, the numerous domains of cognition being assessed (ie, global cognition, memory, executive function, etc) prevent comparisons of study results. Few studies tested similar domains of cognition, and thus it is unclear if sedentary behaviour is associated with decrease in global cognitive function, several different domains of cognition or just a single domain. Future studies therefore need to first determine which domains of cognitive function decrease with increased sedentary behaviour. One means of potentially assessing all domains of cognitive function concomitantly would be the use of the NIH toolbox, ${ }^{76}$ which could independently examine the associations of sedentary behaviour with memory, executive function, and so forth.

Several of the measures used to assess cognitive function in these studies also lacked evidence of validity or reliability, and thus the conclusions may not be valid for the construct the authors planned to investigate. ${ }^{77}$ For example, Hamer and Stamatakis ${ }^{23}$ used a memory test (ie, delayed word recall) without evidence of validity or reliability; thus, rather than measuring memory, the test may be related to another construct, such as executive function.

While there are some issues with measurement of cognitive function in these studies, our preliminary findings suggest sedentary behaviour is negatively associated with memory, executive function and global cognition. These findings suggest sedentary behaviour has a similar association with cognition as exercise and moderate-to-vigorous physical activity. Moderate-to-vigorous physical activity, as well as aerobic and resistance exercise, is well documented to affect multiple domains of cognitive function. ${ }^{78}$ Furthermore, moderate-to-vigorous physical activity and exercise are established as an all-cause dementia prevention measure which could reduce the incidence of all-cause dementia by as many as 1 million cases worldwide. ${ }^{79}$ Given this information, sedentary behaviour may be adversely associated with the same 
neurophysiological pathways as moderate-to-vigorous physical activity and exercise.

\section{Study quality}

The STROBE checklist for observational studies is designed to ensure important information on study design is available, so readers of research can follow what was planned, what was done, what was found and what conclusions can be drawn. ${ }^{22}$ This information is an important component for systematic reviews; ${ }^{80} 81$ however, when components required by the STROBE guidelines are absent, the conclusions which can be drawn from these studies suffer.

The quality of studies we reviewed varied greatly with several of the studies showing multiple flaws in reporting. Only one study ${ }^{24}$ met all criteria of the STROBE, and several studies were missing multiple criteria. Issues such as sampling bias, selection bias, recall bias and detection bias may therefore have inflated the results of these studies. We therefore recommend future investigations on how sedentary behaviour is associated with cognitive function firmly adhere to the STROBE guidelines.

Finally, the lack of a sample size calculation by any of the studies we reviewed is an important concern. Sample size calculations for observational studies require a compromise between balancing the needs of power, economy and timeliness. ${ }^{82}$ Failure to attain a sample size with enough power inevitably leads to type II error; however, equally erroneous is using a sample size that is 'too big' that detects an effect of little scientific importance. ${ }^{83}$ For example, one study we reviewed included well over 6000 participants $^{23}$ which may have accounted for the significant, albeit small, results.

\section{Recommendations}

Current physical activity guidelines offer a brief policy recommendation on sedentary behaviour-avoid it as much as possible ${ }^{84} 85$ however, in order to best promote healthy cognitive ageing, an empirically derived public health message is still needed. Thus, we have developed healthy cognitive ageing guidelines for sedentary behaviour which are in line with current evidence and recommendations. ${ }^{17} 188586$ We therefore recommend all adults should (1) avoid sedentary time wherever possible; (2) limit discretionary sitting time to $<2 \mathrm{~h} /$ day; (3) stand up and move after $30 \mathrm{~min}$ of uninterrupted sitting and (4) increase light-intensity activity (ie, standing and light walking) to $>2 \mathrm{~h} /$ day by substituting these activities for sedentary time (eg, stand while watching television).

Combating a sedentary lifestyle - and associated cognitive declines-also requires an emphasis on encouraging adults to engage in $\geq 150 \mathrm{~min} /$ week of moderate-to-vigorous physical activity. Regular moderate-to-vigorous physical activity is a pillar of healthy cognitive ageing, with current evidence suggesting $\geq 150 \mathrm{~min} /$ week of moderate-to-vigorous physical activity reduces the risk of Alzheimer's disease by $38 \% .{ }^{87}$ Moreover, empirical evidence has found a strong and consistent relationship between moderate-to-vigorous physical activity and cognitive function. Given the current evidence, we recommend all adults limit discretionary sedentary behaviour to $<2 \mathrm{~h} /$ day and concomitantly engage in $\geq 150 \mathrm{~min} /$ week of moderate-to-vigorous physical activity. Meeting these recommendations may best promote healthy cognitive ageing and could reduce the incidence of all-cause dementia by more than 1 million cases worldwide. ${ }^{6}$

\section{Limitations and future directions}

This review only investigated observational studies on how sedentary behaviour is associated with cognitive function; however, to our knowledge, this is the first systematic review to evaluate the evidence. There may also be a publication bias which limits the generalisability of our findings; however, this limitation is inherent in all systematic reviews. Our systematic review located only eight studies, but our findings do show a consistent relationship that sedentary behaviour is associated with poorer cognitive function. Although all four high-quality studies found sedentary behaviour is associated with poorer cognition, ${ }^{23-26}$ more high-quality studies are needed before estimates can be made about the attributable risk of sedentary behaviour to cognitive impairment and all-cause dementia.

Given this area of research is still developing, our study only provides an initial platform for examining the association of sedentary behaviour with cognitive impairment and all-cause dementia. Our preliminary recommendations for healthy cognitive ageing are therefore broadly consistent with current policy ${ }^{17} 188586$ and may need to be refined as more evidence emerges.

Dementia is also a complex disease which has several forms including Alzheimer's disease and vascular dementia, which have vastly different aetiologies. While the mechanisms may be different by which the different subtypes of dementia occur, there are certainly similarities in terms of risk factors. For example, Laurin and colleagues found increased moderate-to-vigorous physical activity was associated with reduced risks of cognitive impairment and dementia of any type. ${ }^{87}$ Thus, our preliminary findings suggest reduced cognitive function and increased all-cause dementia risk are associated with a sedentary lifestyle. Future studies should determine the associations of sedentary behaviour with different types of dementia.

Related to this issue, different types of sedentary behaviour may have different associations with cognitive function. For example, there is some evidence that computer use may positively affect cognitive function in later life. ${ }^{24-26}$ However, since only eight studies assessing sedentary behaviour were included in this review-and only three studies ${ }^{24-26}$ assessed computer use as an exposure variable-it would be difficult to make comparisons and draw conclusions from the available literature. Future studies are therefore needed to determine how different sedentary activities, such as computer use, moderate the relationship between sedentary behaviour and cognitive function.

\section{CONCLUSIONS}

The current body of evidence suggests sedentary behaviour is negatively associated with cognitive function; however, the associations between sedentary behaviour and cognitive function are complex and largely dependent on the exposure variable and outcomes assessed. Nonetheless, our findings suggest reducing discretionary sedentary time to $<2 \mathrm{~h} /$ day and concomitantly engaging in $\geq 150 \mathrm{~min} /$ week of moderate-to-vigorous physical activity may best promote healthy cognitive ageing.

Acknowledgements This work was supported by funding from the Jack Brown and Family Alzheimer Research Foundation Society. RSF is funded by the University of British Columbia Rehabilitation Sciences Doctoral Award. JCD is a Canadian Institutes of Health Research postdoctoral fellow. TL-A is a Canada Research Chair in Physical Activity, Mobility and Cognitive Neuroscience.

Contributors RSF wrote the first draft of the manuscript. JCD provided help with article review and drafting of tables. TLA and JCD conceived the study concept and design. TLA and JCD wrote portions of the manuscript and critically reviewed the manuscript.

Funding Jack Brown and Family Alzheimer Research Foundation Society.

Competing interests None declared.

Provenance and peer review Not commissioned; externally peer reviewed. 


\section{REFERENCES}

World Health Organization. Dementia: a public health priority. Geneva, Switzerland, 2012:112.

2 Launer LJ, Andersen K, Dewey ME, et al. Rates and risk factors for dementia and Alzheimer's disease results from EURODEM pooled analyses. Neurology 1999;52: 78-84.

3 Cohen JE. Human population: the next half century. Science 2003;302:1172-5.

4 Landry GJ, Liu-Ambrose T. Buying time: a rationale for examining the use of circadian rhythm and sleep interventions to delay progression of mild cognitive impairment to Alzheimer's disease. Front Aging Neurosci 2014:6:325.

5 ten Brinke LF, Bolandzadeh N, Nagamatsu LS, et al. Aerobic exercise increases hippocampal volume in older women with probable mild cognitive impairment: a 6-month randomised controlled trial. Br J Sports Med 2015;49:248-54.

6 Hamer M, Chida Y. Physical activity and risk of neurodegenerative disease: a systematic review of prospective evidence. Psychol Med 2009;39:3-11.

7 Nelson ME, Rejeski WJ, Blair SN, et al. Physical activity and public health in olde adults: recommendation from the American College of Sports Medicine and the American Heart Association. Med Sci Sports Exerc 2007;39:1435-45.

8 Haskell WL, Lee IM, Pate RR, et al. Physical activity and public health: updated recommendation for adults from the American College of Sports Medicine and the American Heart Association. Med Sci Sports Exerc 2007;39:1423-34.

9 Pate RR, Pratt M, Blair SN, et al. Physical activity and public health: a recommendation from the Centers for Disease Control and Prevention and the American College of Sports Medicine. JAMA 1995;273:402-7.

10 Troiano RP, Berrigan D, Dodd KW, et al. Physical activity in the United States measured by accelerometer. Med Sci Sports Exerc 2008;40:181-8.

11 Norton S, Matthews FE, Barnes DE, et al. Potential for primary prevention of Alzheimer's disease: an analysis of population-based data. Lancet Neurol 2014;13:788-94

12 Owen N, Bauman A, Brown W. Too much sitting: a novel and important predictor of chronic disease risk? Br J Sports Med 2009;43:81-3.

13 Pate RR, O'Neill JR, Lobelo F. The evolving definition of "sedentary." Exerc Sport Sci Rev 2008;36:173-8.

14 Owen N, Healy GN, Matthews CE, et al. Too much sitting: the population-health science of sedentary behavior. Exerc Sport Sci Rev 2010;38:105-13.

15 Ford ES, Caspersen CJ. Sedentary behaviour and cardiovascular disease: a review of prospective studies. Int J Epidemiol 2012;41:1338-53.

16 Booth FW, Krupa DJ. Sedentary death syndrome is what researchers now call America's second largest threat to public health. Medical Pharmacology and Physiology publications (MU), 2001

17 Owen N, Sugiyama T, Eakin EE, et al. Adults' sedentary behavior determinants and interventions. Am J Prev Med 2011;41;189-96.

18 Buckley JP, Hedge A, Yates $T$, et al. The sedentary office: an expert statement on the growing case for change towards better health and productivity. $\mathrm{Br} / \mathrm{Sports}$ Med 2015;49:1357-62.

19 Vaynman S, Gomez-Pinilla F. Revenge of the "sit": how lifestyle impacts neuronal and cognitive health through molecular systems that interface energy metabolism with neuronal plasticity. J Neurosci Res 2006;84:699-715.

20 Voss MW, Carr LJ, Clark R, et al. Revenge of the "sit" II: does lifestyle impact neuronal and cognitive health through distinct mechanisms associated with sedentary behavior and physical activity? Ment Health Phys Act 2014;7:9-24.

21 Moher D, Liberati A, Tetzlaff J, et al. Preferred reporting items for systematic reviews and meta-analyses: the PRISMA statement. Ann Intern Med 2009;151:264-9.

22 von Elm E, Altman DG, Egger M, et al. The Strengthening the Reporting of Observational Studies in Epidemiology (STROBE) statement: guidelines for reporting observational studies. Prev Med 2007:45:247-51.

23 Hamer M, Stamatakis E. Prospective study of sedentary behavior, risk of depression, and cognitive impairment. Med Sci Sports Exerc 2014:46:718-23.

24 Kesse-Guyot E, Andreeva VA, Lassale C, et al. Clustering of Midlife Lifestyle Behaviors and Subsequent Cognitive Function: A Longitudinal Study. Am J Public Health 2014;104:e170-e77.

25 Kesse-Guyot $E$, Charreire $H$, Andreeva VA, et al. Cross-sectional and longitudinal associations of different sedentary behaviors with cognitive performance in older adults. PLOS ONE 2012;7:e474831

26 Kivipelto M, Rovio S, Ngandu T, et al. Apolipoprotein E epsilon4 magnifies lifestyle risks for dementia: a population-based study. J Cell Mol Med 2008;12:2762-71.

27 Lindstrom HA, Fritsch T, Petot $\mathrm{G}$, et al. The relationships between television viewing in midlife and the development of Alzheimer's disease in a case-control study. Brain Cogn 2005;58:157-65.

28 Rosenberg DE, Bellettiere J, Gardiner PA, et al. Independent Associations Between Sedentary Behaviors and Mental, Cognitive, Physical, and Functional Health Among Older Adults in Retirement Communities. J Gerontol A Biol Sci Med Sci 2016;71:78-83.

29 Steinberg SI, Sammel MD, Harel BT, et al. Exercise, sedentary pastimes, and cognitive performance in healthy older adults. Am J Alzheimers Dis Other Demen 2015:30:290-8.
30 Vance DE, Wadley VG, Ball KK, et al. The effects of physical activity and sedentary behavior on cognitive health in older adults. J Aging Phys Act 2005;13:294-313.

31 Wilson RS, Leurgans SE, Boyle PA, et al. Neurodegenerative basis of age-related cognitive decline. Neurology 2010;75:1070-8.

32 Vuillemin A, Oppert JM, Guillemin F, et al. Self-administered questionnaire compared with interview to assess past-year physical activity. Med Sci Sports Exerc 2000:32:1119-24.

33 Wechsler D. WAIS-R manual: Wechsler adult intelligence scale-revised. Psychological Corporation, 1981

34 Delis DC, Kaplan E, Kramer JH. Delis-Kaplan executive function system (D-KEFS). Psychological Corporation, 2001.

35 Ivanoiu A, Adam S, Van der LM, et al. Memory evaluation with a new cued recall test in patients with mild cognitive impairment and Alzheimer's disease. J Neurol 2005;252:47-55.

36 Lezak MD. Neuropsychological assessment. Oxford university press, 2004.

37 Folstein MF, Folstein SE, McHugh PR. "Mini-mental state". A practical method for grading the cognitive state of patients for the clinician. J Psychiatr Res 1975:12:189-98.

38 Cooper AM, Michels R. Diagnostic and statistical manual of mental disorders, revised (DSM-III-R). Am J Psychiatry 1988;145:1300-12.

39 Rosenberg DE, Norman GJ, Wagner N, et al. Reliability and validity of the Sedentary Behavior Questionnaire (SBQ) for adults. J Phys Act Health 2010;7:697-705

40 Bassett DR Jr, Rowlands A, Trost SG. Calibration and validation of wearable monitors. Med Sci Sports Exerc 2012;44(1 Suppl 1):S32-8.

41 Reitan RM. Validity of the Trail Making Test as an indicator of organic brain damage. Percept Mot Skills 1958;8:271-6.

42 Hekler EB, Buman MP, Haskell WL, et al. Reliability and validity of CHAMPS self-reported sedentary-to-vigorous intensity physical activity in older adults. J Phys Act Health 2012;9:225-36.

43 Hammers D, Spurgeon E, Ryan K, et al. Validity of a brief computerized cognitive screening test in dementia. J Geriatr Psychiatry Neurol 2012;25:89-99.

44 Fried LP, Borhani NO, Enright $\mathrm{P}$, et al. The cardiovascular health study: design and rationale. Ann Epidemiol 1991;1:263-76.

45 Sivan AB. Benton visual retention test. San Antonio, TX: Psychological Corporation, 1992.

46 Lezak M. Neuropsychological testing. Oxford: University Press, 1995.

47 Pettee Gabriel K, McClain JJ, Schmid KK, et al. Reliability and convergent validity of the past-week Modifiable Activity Questionnaire. Public Health Nutr 2011;14:435-42.

48 Choi L, Liu Z, Matthews CE, et al. Validation of accelerometer wear and nonwear time classification algorithm. Med Sci Sports Exerc 2011;43:357-64.

49 Freedson PS, Melanson E, Sirard J. Calibration of the Computer Science and Applications, Inc. accelerometer. Med Sci Sports Exerc 1998;30:777-81.

50 Cyarto EV, Marshall AL, Dickinson RK, et al. Measurement properties of the CHAMPS physical activity questionnaire in a sample of older Australians. I Sci Med Sport 2006;9:319-26.

51 Harrison JE, Buxton $\mathrm{P}$, Husain $\mathrm{M}$, et al. Short test of semantic and phonologica fluency: Normal performance, validity and test-retest reliability. Br J Clin Psychol 2000;39:181-91.

52 Tulsky DS, Price LR. The joint WAIS-III and WMS-III factor structure: development and cross-validation of a six-factor model of cognitive functioning. Psychol Assess 2003:15:149-62.

53 Sánchez-Cubillo I, Periáñez J, Adrover-Roig D, et al. Construct validity of the Trail Making Test: role of task-switching, working memory, inhibition/interference control, and visuomotor abilities. J Int Neuropsychol Soc 2009;15:438-50.

54 Spreen 0, Strauss E. A compendium of neurological tests. 2nd edn. New York: Oxford University Press, Inc., 1998.

55 Maruff $P$, Thomas E, Cysique L, et al. Validity of the CogState brief battery: relationship to standardized tests and sensitivity to cognitive impairment in mild traumatic brain injury, schizophrenia, and AIDS dementia complex. Arch Clin Neuropsychol 2009;24:165-78.

56 Salthouse TA. When does age-related cognitive decline begin? Neurobiol Aging 2009:30:507-14.

57 Hedden T, Gabrieli JD. Insights into the aging mind: a view from cognitive neuroscience. Nat Rev Neurosci 2004;5:87-96.

58 Hill $A B$. The environment and disease: association or causation? Proc RSoc Med $1965 \cdot 58 \cdot 295-300$.

59 Tremblay MS, Colley RC, Saunders TJ, et al. Physiological and health implications of a sedentary lifestyle. App/ Physiol Nutr Metab 2010;35:725-40.

60 Panza F, D'Introno A, Colacicco AM, et al. Lipid metabolism in cognitive decline and dementia. Brain Res Rev 2006;51:275-92.

61 Craft S. The Role of Metabolic Disorders in Alzheimer Disease and Vascular Dementia. Arch Neurol 2009;66:300-5.

62 Lees SJ, Booth FW. Sedentary death syndrome. Can J Appl Physiol 2004;29:447-60.

63 Stewart R, Liolitsa D. Type 2 diabetes mellitus, cognitive impairment and dementia. Diabetic Med 1999;16:93-112. 
64 Pinkston JB, Alekseeva N, González Toledo E. Stroke and dementia. Neurol Res 2009;31:824-31.

65 Newman AB, Fitzpatrick AL, Lopez O, et al. Dementia and Alzheimer's disease incidence in relationship to cardiovascular disease in the Cardiovascular Health Study cohort. J Am Geriatr Soc 2005;53:1101-7.

66 Troiano RP. Can there be a single best measure of reported physical activity? Am J Clin Nutr 2009;89:736-7.

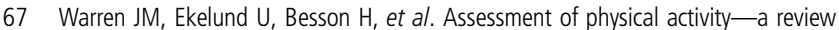
of methodologies with reference to epidemiological research: a report of the exercise physiology section of the European Association of Cardiovascular Prevention and Rehabilitation. Eur J Cardiovasc Prev Rehabil 2010;17:127-39.

68 Lee I-M, Shiroma EJ. Using accelerometers to measure physical activity in large-scale epidemiological studies: issues and challenges. Br J Sports Med 2014;48:197-201.

69 Harada ND, Chiu V, King AC, et al. An evaluation of three self-report physical activity instruments for older adults. Med Sci Sports Exerc 2001;33:962-70.

70 Podsakoff PM, MacKenzie SB, Lee JY, et al. Common method biases in behaviora research: a critical review of the literature and recommended remedies. J Appl Psychol 2003:88:879-903.

71 Martin A, Fitzsimons C, Jepson R, et al. Interventions with potential to reduce sedentary time in adults: systematic review and meta-analysis. $\mathrm{Br} J$ Sports Med 2015:49:1056-63.

72 Atkinson G, Nevill AM. Statistical methods for assessing measurement error (reliability) in variables relevant to sports medicine. Sports Med 1998;26:217-38.

73 Safrit MJ, Wood TM. Measurement concepts in physical education and exercise science. Human Kinetics Books, 1989

74 Falck RS, McDonald SM, Beets MW, et al. Measurement of physical activity in olde adult interventions: a systematic review. Br J Sports Med 2016:50:464-70.
75 Nasreddine ZS, Philips NA, Bédirian V, et al. The Montreal Cognitive Assessment, MoCA: abrief screening tool for mild cognitive impairment. J Am Geriatr Soc 2005;53:695-9.

76 Weintraub S, Dikmen SS, Heaton RK, et al. Cognition assessment using the NIH Toolbox. Neurology 2013;80(Supplement 3):S54-64.

77 Hubley AM, Zumbo BD. Validity and the consequences of test interpretation and use. Soc Indic Res 2011;103:219-30.

78 Nagamatsu LS, Flicker L, Kramer AF, et al. Exercise is medicine, for the body and the brain. Brit J Sports Med 2014:48:943-4.

79 Barnes DE, Yaffe K. The projected effect of risk factor reduction on Alzheimer's disease prevalence. Lancet Neurol 2011;10:819-28.

80 Jüni $P$, Altman DG, Egger M. Assessing the quality of controlled clinical trials. BMJ 2001;323:42-6.

81 Egger M, Schneider M, Smith GD. Meta-analysis Spurious precision? Meta-analysis of observational studies. BMJ 1998;316:140-4.

82 Dupont WD, Plummer WD Jr. Power and sample size calculations: a review and computer program. Control Clin Trials 1990;11:116-28.

83 Lenth RV. Some practical guidelines for effective sample size determination. Am Stat 2001;55:187-93.

84 Physical Activity Guidelines for Americans. Bethesda, MD: National Institute of Health, 2008:76.

85 Hamilton MT, Healy GN, Dunstan DW, et al. Too Little Exercise and Too Much Sitting: Inactivity Physiology and the Need for New Recommendations on Sedentary Behavior. Current Cardiovasc Risk Rep 2008;2:292-8.

86 Thorp AA, Owen N, Neuhaus M, et al. Sedentary behaviors and subsequent health outcomes in adults a systematic review of longitudinal studies, 1996-2011. Am J. Prev Med 2011;41:207-15.

87 Laurin D, Verreault R, Lindsay J, et al. Physical activity and risk of cognitive impairment and dementia in elderly persons. Arch Neurol 2001:58:498-504. 